\title{
Mango malformation: II. mangiferin changes associated with fusarium pathogens
}

\author{
Wafaa M. Haggag ${ }^{1^{\star}}$, Mahmoud Hazza², Mohamed E. Abd El-Wahab ${ }^{1}$ \\ ${ }^{1}$ Department of Plant Pathology, National Research Center, Dokki, Cairo, Egypt; \\ ${ }^{2}$ Science Faculty, Botany Department, Banha University, Egypt; Corresponding Author: Wafaa haggag@yahoo.com
}

Received 16 February 2011; revised 23 May 2011; accepted 25 July 2011.

\begin{abstract}
Mangiferin (1,3,6,7-tetrahydroxy xanthone-C2-bD-glucoside) promoted vegetative growth and exhibited inhibitory role on the occurrence of malformation. Mangiferin changes associated with mango malformation pathogens were followed after inoculated mango seedlings (three years) with malformation pathogens i.e. Fusarium subglutinans, F. sterilihyphosum, F. oxysporum and $F$. proliferatum. Mangiferin remained at lower level in leaves of malformed shoots as compared to healthy one. The floral malformation was observed to be associated with the reduction of mangiferin. Strong positive correlations between mangiferin activity and malformation incidence were observed. Mangiferin level at panicle initiation may give a possible estimate of malformation incidence in mango.
\end{abstract}

Keywords: Fusarium; Mangiferin; Mango Malformation

\section{INTRODUCTION}

Mango (Mangifera indica L.) is the most important fruit crop in Egypt. Mango ranks third in exports after citrus and grapes. Egypt produces 232,000 tones of mango annually and exports moderate amount (about 1500 tones) annually to 20 countries in near east and Europe (FAO, 2007).

Mango Malformation is one of the most destructive mango diseases [1]. Accumulation of mangiferin and toxic metabolites of Fusarium moniliforme has been suggested to be responsible for the malformation disease of mango (Mangifera indica L.). Differences in the lowand medium $\mathrm{M}$, phenolic and steroidal compounds in healthy and malformed florets of Mangifera indica, the latter infested with Fusarium moniliforme var. subglutinans are reported. Mangiferin, which are not normal constituents of healthy florets were found in substantial amounts in the diseased florets. Both mangiferin and 1,3, 6,7-tetrahydroxyxanthone were found to be potent antifungal agents[2]. Accumulation of mangiferin, a natural metabolite of Mangifera indica at the site of differentiating buds, influences the changes from reproductive to vegetative growth. Mangiferin in high concentration suppressed the activity of peroxidase, catalase, $\alpha$-amylase and IAA-oxidase. Polyphenoloxidase and invertase showed increased activity. Mangiferin accumulation increased the rate of photosynthesis but lowered those of transpiration and respiration. Mangiferin treatment increased the contents of chlorophyll, carbohydrates, total nitrogen, protein nitrogen, nucleic acids (RNA and DNA) and indole-3yl-acaetic acid (IAA) [3]. Mangiferin acts as a phytoalexin-like compound in $M$. indica. Nonpathogenic strains of $F$. moniliforme isolated from maize $\mathrm{cob}$ and banana fruits induced more mangiferin synthesis than the pathogenic isolate from malformed mango shoots in vivo. Activity of the mangiferin degrading enzymes, polyphenoloxidase of non-pathogenic strains of $F$. moniliforme was higher than that of the pathogenic strain. In vitro tests also confirmed rapid and massive degradation of mangiferin by non-pathogenic strains. Biochemical events associated with elicitation, degradation and accumulation of mangiferin determine the host specificity of $F$. moniliforme in $M$. indica [4]. At the stages of bud pre-emergence and initial differentiation, mangiferin content in the leaves from the axils of which healthy and malformed buds emerged did not show significant differences although in the latter one mangiferin content was higher. But in the fully developed panicles at pre-blooming stage mangiferin content of the leaves attached to the malformed panicle was in traces and significantly lower than that of healthy one. Mangiferin content in malformed panicles also did not differ significantly at the initial stage. But the difference become highly significant after influx of mangiferin from axil leaves to the fully developed panicle at pre-blooming 
stage. Mangiferin due to its vegetative growth promoting property tilted the hormonal balance of malformed panicles in favour of vegetative growth resulting into transformation of malformed florets into green leafy structures [5]. The mangiferin treated strains produced more aerial hyphae but less pigment. Prolonged mangiferin treatment affected the saprophytic ability of the strains but improved its parasitism. The significance of mangiferin induced changes in evolving the host-specific strain of $F$. moniliforme of $M$. indicia lies in showing that an ecological disadvantage of survival in one niche (saprophytic) may prove advantageous in another (parasite) [8]. The fungal and mite populations were initially positively related to the mangiferin content and the disease incidence. Further increase in mangiferin content reduced the fungal and mite populations [6]. The symptoms are the combined effects of aberrant host metabolites produced in response to infection and phytotoxins secreted by the pathogen. The pathogen has been identified as a physiological race of $F$. moniliforme ( $F$. moniliforme $f$. $s p$. mangifera) developed due to interaction with the host metabolite, mangiferin for a prolonged period. The disease cycle is greatly influenced with the biochemical changes in the host tissues. Host metabolites also effect the seasonal variation of population of the pathogen Vis-a-Vis disease incidence. Proper balance of mangiferin and the Fusarium population is required for disease manifestation. Either by suppressing or avoiding elicitation of hypersensitive reaction of the host at the initial stage of infection, colonization by the pathogen and subsequent symptom production could be effected [3].Thus, objective of the present study is to evaluate mangiferin change in mango plant due to infection with pathogenic fungi.

\section{MATERIALS AND METHODS}

Mango (Mangifera indica L.) seedling cv. Sedekia (three years old) was inoculated with 105 colony forming units of Fusarium spp. i.e. F. subglutinans, F. sterilihyphosum, $F$. oxysporum and $F$. proliferatum, the causal organisms of mango malformation as inoculated soil. Sterilized water was used as a control. Transplanted seedlings were monitored for development of malformation. At the end of the experiment (120 days), all surviving seedlings were examined for apical disease symptoms. Samples for mangiferin study were taken from leaves one-two cm below the tip of young seedlings.

\subsection{Isolation of Mangiferin}

The leaves were macerated with acetone in a high speed blender. After $4 \mathrm{~h}$, the mixture was filtered and the solvent was removed under pressure. The extractions were poured into $100 \mathrm{ml}$ distilled water and the suspension was successfully extracted with ether and ethyl acetate. At the interface of the aqueous ethyl acetate, brown solid mass was precipitated and this was collected by filtration. The identity of the brown residue was determined as mangiferin according to Ghosal et al. [2]. Subsequently, a small volume of the extract was filtered through $13 \mathrm{~mm}$ membrane filter $(0.45 \mu \mathrm{m}$; polypropylene) directly into HPLC sample vial for injection without further dilution.

\subsection{Mangiferin Analysis}

Extract were done using HPLC system (prominence Lc, Shimaduz, Kyoto, Japan) equipped with a Lichrospher 100RP-18 $(5 \mu \mathrm{m})$ column $(250 \mathrm{~mm} \times 4 \mathrm{~mm}$, Merck, Darmstadt, Germany), a $\mathrm{C}_{18}$ guard column and a photoiode-array detector (Shimadzu, SPD-M20A). THE elution system $\left(0.8 \mathrm{~mL} \cdot \mathrm{min}^{-1}\right)$ involved $2 \mathrm{mM}$ phosphoric acid in water (eluent $\mathrm{A}$ ) and $\mathrm{MeOH}$ (eluent $\mathrm{B}$ ). The gradient was as follows: $0 \mathrm{~min}, 25 \%$ eluent B, 0 - $40 \mathrm{~min}$, $80 \%$ eluent $\mathrm{B}$, linear the retention time and spectral characteristics of each sample were compared to a reference sample of mangiferin (Extrasynthese, Lyon, France) [7].

\subsection{HPLC Analysis and Method Development}

The HPLC system consisted of a ternary solvent pump (Gynkotek Model 480), autosampler (Gynkotek Gina 50), decade electrochemical detector with a glassy carbon electrode (Antec) and a diode array detector (Gynkotek 340 S). Gynko soft software V5.60 was used to control the HPLC system and for data acquisition and analysis. The equipment was supplied by Dionex Softron (Idstein, Germany). Three columns, i.e. Multosphere C18 (3 $\mu \mathrm{m} ; 125 ; 4$ mm ID), Phenomenex Synergy MAX-RP C12 80 A with TMS end-capping (4 $\mu \mathrm{m} ; 150$; $4.6 \mathrm{~mm}$ ID) and Phenomenex Synergi Polar RP (ether linkedphenyl phase with polar end-capping) were tested for the chromatographic separation of the above-mentioned substances. The Multosphere column was purchased from CS, Langer-wehe, Germany and Phenomenex, Aschaffenburg, Germany supplied the Phenomenex columns. Peak identify was determined by means of retention time and UV spectra that were recorded for all samples $250 \mathrm{~nm}$. During method development, three solvent gradients were tested: program I: 0 - 6 min $(12 \% \mathrm{~B}), 7$ $\min (18 \%$ B), $14 \min (25 \%$ B), $19 \min (40 \%$ B), $24 \min$ $(50 \% \mathrm{~B}), 29 \min (12 \% \mathrm{~B})$ (solvent $\mathrm{A}=2 \%$ acetic acid in aqueous solution (v/v) and solvent $\mathrm{B}=$ acetonitrile); program II: $0 \min (5 \% \mathrm{~B}, 5 \% \mathrm{C}) ; 4,5 \min (6,5 \% \mathrm{~B}, 5 \%$ C), $7 \min (18 \% \mathrm{~B}), 14 \min (25 \% \mathrm{~B}), 19 \min (40 \% \mathrm{~B}), 24$ 
$\min (50 \% \mathrm{~B}), 30 \min (5 \% \mathrm{~B}, 5 \% \mathrm{C})$ [solvent $\mathrm{A}=2 \%$ acetic acid in aqueous solution $(\mathrm{v} / \mathrm{v})$, solvent $\mathrm{B}=$ acetonitrileand solvent $\mathrm{C}=$ tetrahydrofurane (THF)]; program III: identical to Program I except that solvent A was purified water buffered to $\mathrm{pH} 4$ with citrate buffer. This program, in combination with the Synergy MAX-RP $\mathrm{C}_{12}$ column, was used exclusively for electrochemical detection. In all cases a flow rate of $1 \mathrm{ml} / \mathrm{min}$ was used. The injection volume was $20 \mu \mathrm{l}$ for each analysis and separations were carried out at room temperature. Linear calibration lines for mangiferin were compiled using standard series of six dilutions between 4.7 and $98.3 \mu \mathrm{g} / \mathrm{ml}$. The repeatability of HPLC method was determined by ten injections of the same sample of extracted. The reproductively of the complete assay was tested by means of ten sample preparations [8].

\section{RESULT AND DISCUSSION}

Changes in mangiferin (1,3,6,7-tetrahydroxy xanthoneC2-b-D-glucoside) $\mathrm{C}_{10} \mathrm{H}_{10} \mathrm{O}_{11}$ of healthy and malformed shoots of mango cultivar Sedekia (three years old) was followed after inoculated with mango malformation pathogens i.e. F. subglutinans, F. sterilihyphosum, F. oxysporum and $F$. proliferatum. Data pertaining to artificial inoculations revealed that, Fusarium subglutinans proved to be the dominant fungus with $100 \%$ sample's infection in inoculated soil (Table 1). Fungi $F$. oxysporum, $F$. sterilihyphosum and $F$. proliferatum showed moderate infection in induced typical malformation symptoms in inoculated mango seedling and were reisolated. Changes in mangiferin activity in mango seedlings cv. Sedekia as response to infection with mango malformation pathogens i.e. F. subglutinans, F. sterilihyphosum, $F$. oxysporum and $F$. proliferatum grown under greenhouse was determined. Mangiferin activity varied widely amongst different inoculated pathogens. From the data given in Table 1 and Figure 1, it is clear that accumulation of mangiferin was maximum (0.96 $\left.\mu \mathrm{g} / \mathrm{g}^{-1} \mathrm{FW}\right)$ in leaves of healthy shoots. Mangiferin reduced in mango shoot in response to infection with $F$. sterilihyphosum by $0.52 \mu \mathrm{g} / \mathrm{g}^{-1} \mathrm{FW}$. The amount of mangiferin is $0.15 \mu \mathrm{g} / \mathrm{g}^{-1} \mathrm{FW}$ due to infection with $F$. subglutinis. Mangiferin is detected as $0.12 \mu \mathrm{g} / \mathrm{g}^{-1} \mathrm{FW}$ as result of infection with $F$. proliferatum. It is clear that the least amount of mangiferin is detected as result of infection with $F$. oxysporum $\left(0.0039 \mu \mathrm{g} / \mathrm{g}^{-1} \mathrm{FW}\right)$. Strong positive correlations between mangiferin activity and malformation incidence were observed. Mangiferin promoted vegetative growth and exhibited inhibitory role on the occurrence of malformation. It was also observed that the healthy had highest activity of mangiferin as compared to infected ones. Results of the present study
Table 1. Status of mangiferin in mango shoot explants as influenced by different inoculation with pathogenic fungi.

\begin{tabular}{lcc}
\hline Treatment & Malformation (\%) & Mangiferin $\left(\mu \mathrm{g} / \mathrm{g}^{-1} \mathrm{FW}\right)$ \\
\hline Control & - & 0.96 \\
F. subglutinans & 100 & 0.12 \\
F. sterilihyphosum & 50 & 0.52 \\
F. oxysporum & 50 & 0.0039 \\
F. proliferatum & 50 & 0.15 \\
\hline
\end{tabular}

clearly indicate that level of mangiferin could be consid ered as a potential biochemical indicator for the malformation disease of mango. Interaction among Fusarium moniliforme and colonizing malformed mango panicles, and mangiferin $(1,3,6,7$-tetrahydroxyx-anthone $C 2-\beta$-D glucoside), a defensive metabolite of the host plant in relation to floral malformation, was in- vestigated. The fungal populations were initially positively related to the mangiferin content and the disease incidence. Further increase in mangiferin content reduced the fungal and mite populations; however, the increase in infection rate was not affected until the Fusarium population was too low. The fungal conidia remained adhered to the body surface of the mites inhabiting malformed panicles, and its plating on potato dextrose agar showed a trail of fungal colonies along the pathway of its movement. Tyrolicus casei facilitated the ingress of the fungus into the host cells while $F$. moniliforme served as the feed of T.casei and increased its multiplication [6,9]. Mangiferin acts as a phytoalexinlike compound in M. indica. Activity of the mangiferin degrading enzymes, polyphenoloxidase of non-pathogenic strains of $F$. moniliforme was higher than that of the pathogenic strain. In vitro tests also confirmed rapid and massive degradation of mangiferin by non-pathogenic strains. The disease incidence could be minimized by removing stress factor (the pathogen) through removal of malformed plant parts and supplying the malformed plants necessary micronutrients by spraying with mangiferin metal chelates $[10,11]$. The biochemical significance of the changes in these constituents, resulting from the hypersensitive responses in the host specie, is appraised in respect to the Fusarium pathogens, the causal organisms of mango malformation. 

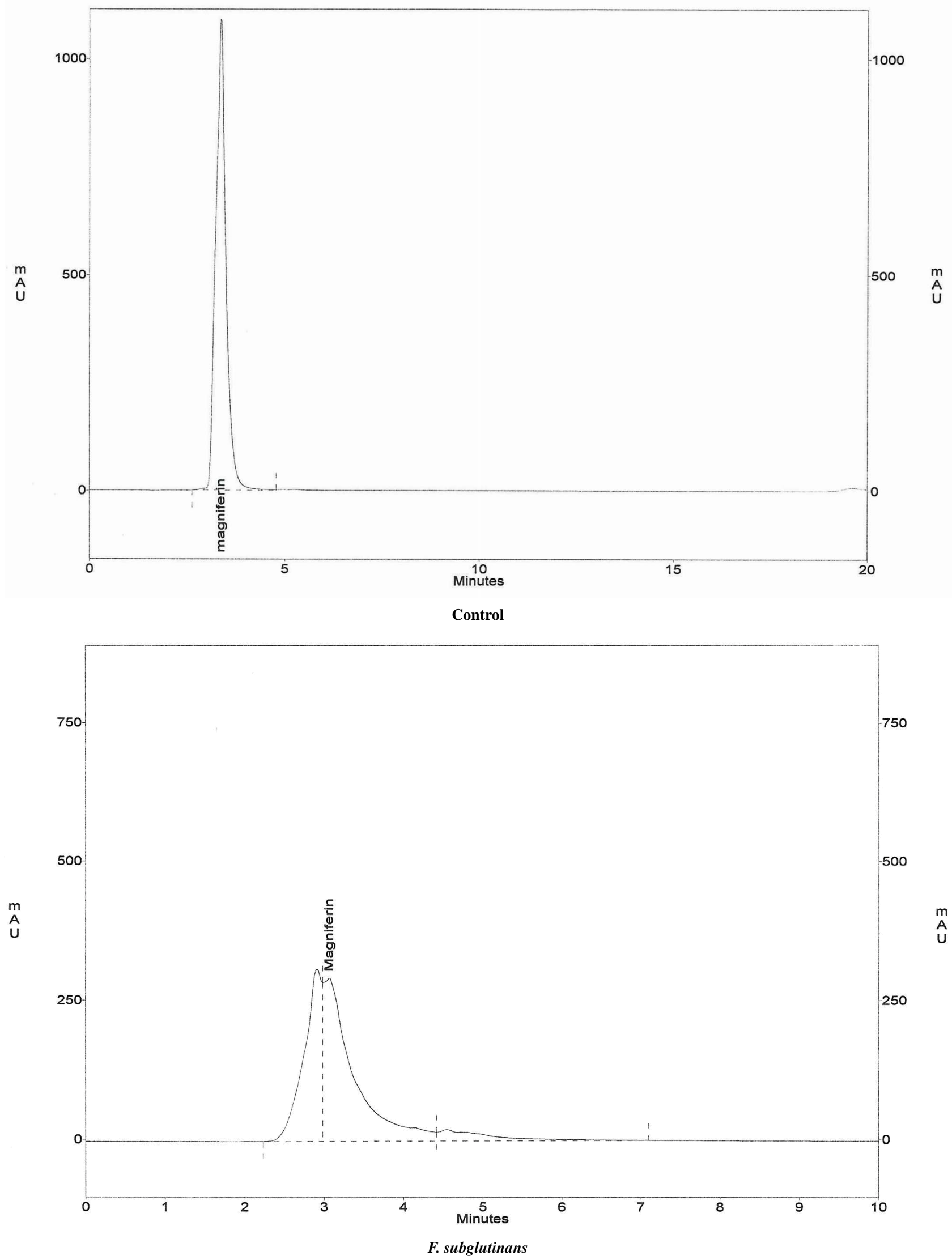

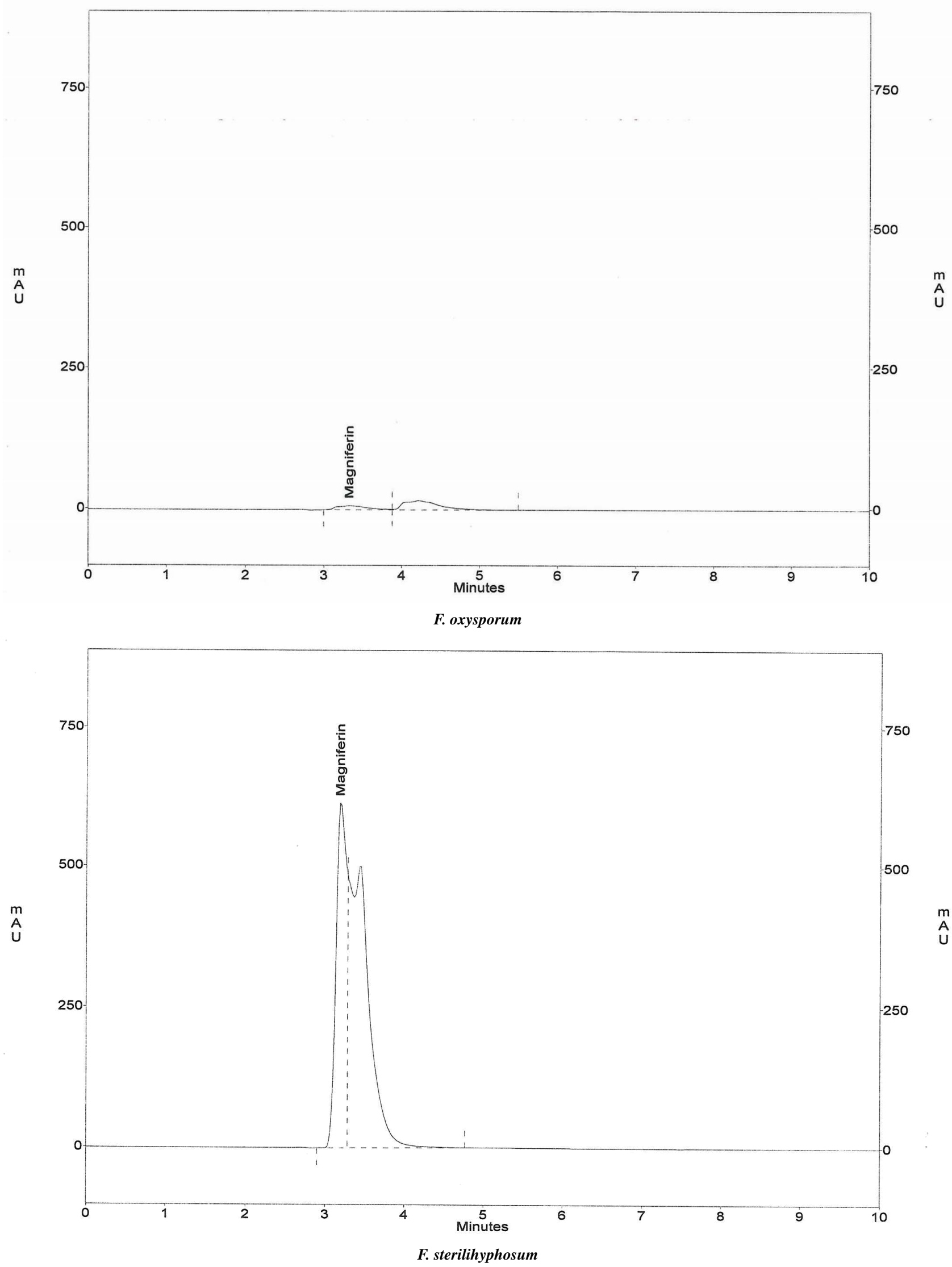


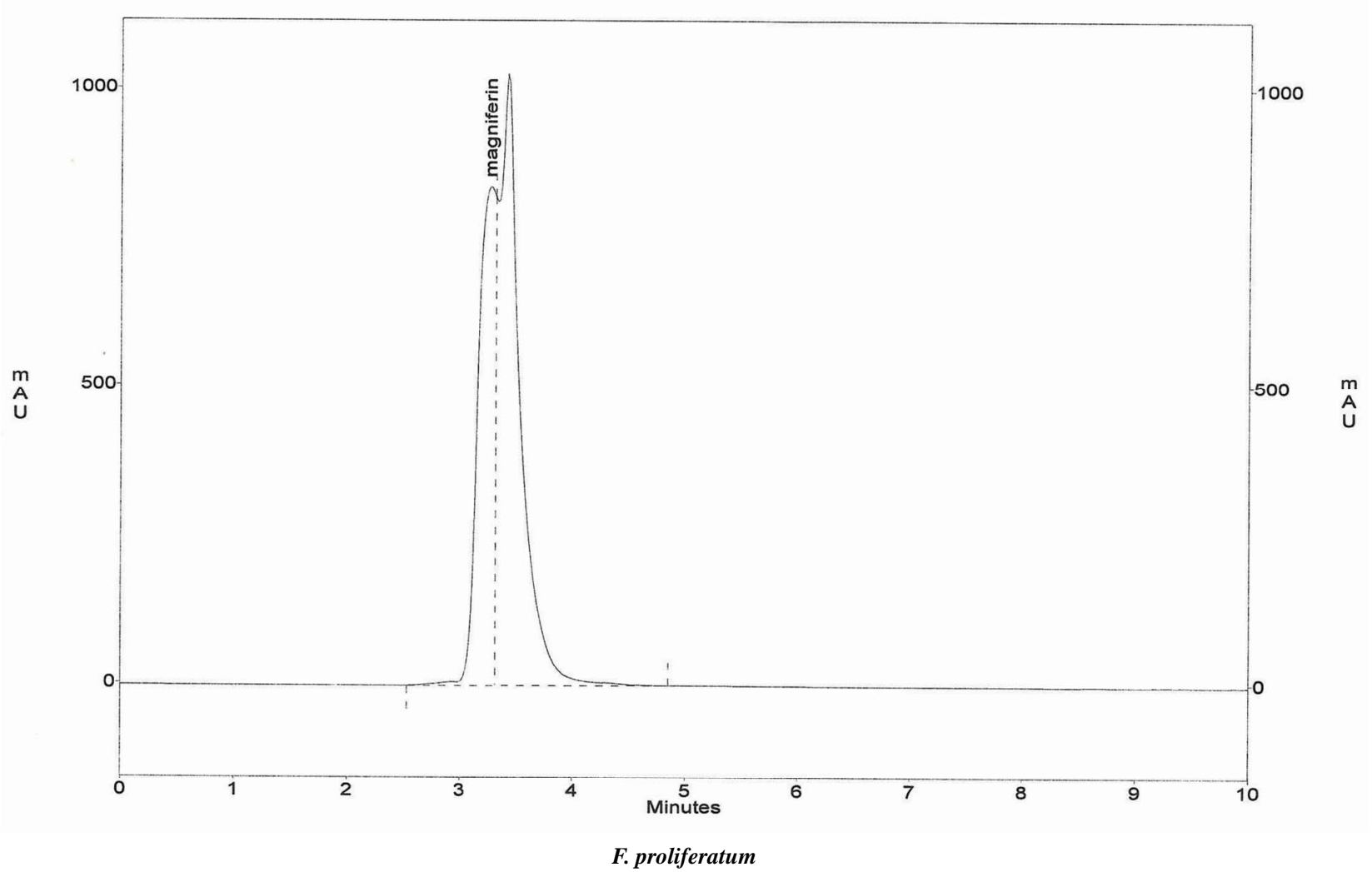

Figure 1. Changes in Mangiferin (1,3,6,7-tetrahydroxy xanthone-C2-b-D-glucoside) $\mathrm{C}_{10} \mathrm{H}_{10} \mathrm{O}_{11}$ of healthy and malformed shoots of mango cultivar Seddek when inoculated with Fusarium pathogens.

\section{ACKNOWLEDGEMENTS}

This manuscript funded from the project "New applied approaches to promote productivity and Quality of some fruit crops (Mango)" PI: Prof. Wafaa M. Haggag. National Research Centre, 2007 to 2010.

\section{REFERENCES}

[1] Ploetz, R.C. (2001) Malformation: A unique and important disease of mango, Mangifera indica L. In: Summerell, B.A., Leslie, J.F., Backhouse, D. and Bryden, W.L., Eds., Fusarium: Paul E. Nelson Memorial Symposium, American Phytopathological Society (APS) Press, St Paul, 233-247.

[2] Ghosal, S., Chakrabarti D.K. and Basuchaudhary, K.C. (1977) Control fusarium wilt of sunflower by mangiferin. Phytopathology, 67, 548-550. doi:10.1094/Phyto-67-548

[3] Chakrabarti, D.K., Singh, A. and Singh, K. (1990) Physiological and biochemical changes induced by accumulated Mangiferin in Mangifera indica, Journal of Horticultural Science, 65, 731-737.

[4] Kumar, R. and Chakrabarti, D.K. (1992) Biochemical evidence of physiological specialization of Fusarium moniliforme Sheld, the incitant of malformation disease of Mangifera indica L. Indian Journal of Experimental Biology, 30, 448-450

[5] Chakrabarti, D.K. and Sharma, R.C. (1993) Mango malformation: Relation of mangiferin concentration in dif- ferentiating buds to abnormal inflorescence of Mangifera indica. Annals of Plant Protection Sciences, 1, 51-53.

[6] Chakrabarti, D.K., Kumar, R. and Kumar, S. (1997) Interaction among Fusarium moniliforme, Tyrolichus casei and mangiferin as related to malformation of Mangifera indica, Tropical Agriculture, 74, 317-320.

[7] Talamond, P., Mondolot, L., Gargadennec, A., Hamon, A.S., Fruchier, A. and Campa, C. (2008) First report on mangiferin (C-glucosyl-xanthone) isolated from leaves of a wild coffee plant, Coffea pseudozangubariae (rubiaceae). Acta Botanica Gallica, 155, 513-819.

[8] Joubert, E. (2003), Revesed-Phase HPLC determination of mangiferin, Isomangiferin and hesperidin in Cyclopia and the effect of harvesting date on phenolic composition of C. genistoides. European Food Research and Technology, 216, 270-273.

[9] Kumar, R. and Chakrabarti, D.K. (1995) Mango malformation: Effect of mangiferin on morphology and parasitism in Fusarium moniliforme, Proceedings of National Symposium on Sustainable Agriculture in Sub-humid Zone, Sriniketan, 348-352

[10] Chakrabarti, D.K. and Kumar, R. (1998) Mango malformation: Role of Fusarium moniliforme and mangiferin. Agricultural Reviews, 19, 126-136.

[11] Ghosal, S. and Chakrabarti, D.K. (1988) Differences in phenolic and steriodal constituents between healthy and infected florets of Mangifera indica, Phytochemistry, 27, 1339-1343. doi:10.1016/0031-9422(88)80189-4 